Article

\title{
Synthesis and Characterization of Efficient $\mathrm{ZnO} / \mathrm{g}-\mathrm{C}_{3} \mathrm{~N}_{4}$ Nanocomposites Photocatalyst for Photocatalytic Degradation of Methylene Blue
}

\author{
Renathung C. Ngullie ${ }^{1}$, Saleh O. Alaswad ${ }^{2}$, Kandasamy Bhuvaneswari ${ }^{3}$, \\ Paramasivam Shanmugam ${ }^{1, *}$, Thangavelu Pazhanivel ${ }^{3}$ and Prabhakarn Arunachalam $4, * \mathbb{D}$ \\ 1 Department of Chemistry, St. Joseph University, Dimapur, Nagaland 797115, India; ngullierena@gmail.com \\ 2 Nuclear Science Research Institute (NSRI), King Abdulaziz City for Science and Technology (KACST), \\ P.O. Box 6086, Riyadh 11442, Saudi Arabia; salaswad@kacst.edu.sa \\ 3 Smart Materials Interface Laboratory, Department of Physics, Periyar University, Salem-636 011, India; \\ bhuviphy11@gmail.com (K.B.); pazhanit@gmail.com (T.P.) \\ 4 Electrochemistry Science Research Chair (ESRC), Chemistry Department, College of Science, \\ King Saud University, Riyadh 11451, Saudi Arabia \\ * Correspondence: shanmugachem@gmail.com (P.S.); parunachalam@ksu.edu.sa (P.A.); \\ Tel.: +91-9884284640 (P.S.); +966-507564123 (P.A.)
}

Received: 13 April 2020; Accepted: 20 May 2020; Published: 23 May 2020

check for updates

\begin{abstract}
We examine the photocatalytic activity (PCA) of $\mathrm{ZnO} /$ graphitic carbon nitride $\mathrm{g}_{-} \mathrm{C}_{3} \mathrm{~N}_{4}$ (g-CN) composite material for methylene blue $(\mathrm{MB})$ degradation under visible-light irradiation (VLI). The polymeric g-CN materials were fabricated by the pyrolysis of urea and thiourea. More importantly, $\mathrm{ZnO} / \mathrm{g}-\mathrm{CN}$ nanostructured composites were fabricated by adding the different mounts $(60,65,70$, and $75 \mathrm{wt} . \%)$ of $\mathrm{g}-\mathrm{CN}$ into $\mathrm{ZnO}$ via the simple hydrothermal process. Among fabricated composites, the $75 \% \mathrm{ZnO} / \mathrm{g}-\mathrm{CN}$ nanocomposites displayed a superior PCA for MB degradation, which were three-fold an enhancement over the pure $\mathrm{ZnO}$ nanoparticles. The fabricated materials have been evaluated by X-ray diffraction (XRD), UV-Vis, Fourier transform infrared (FT-IR) spectroscopy, and electron microscopy. More importantly, the photodegradation of $\mathrm{MB}$ could get $98 \%$ in $\mathrm{ZnO} / \mathrm{g}-\mathrm{CN}$ could be credited to efficient separation of photo-induced charge carriers between $\mathrm{ZnO}$ and g-CN. Also, the recycling efficiency of the as-prepared composites was studied for multiple cycles, which shows that the photocatalysts are stable and suitable to carry out photocatalytic degradation in the logistic mode. Additionally, the probable photocatalytic mechanism has also discussed. The synthetic procedure of $\mathrm{ZnO} / \mathrm{g}-\mathrm{CN}$ based materials can be used in numerous fields such as environmental and in energy storage applications.
\end{abstract}

Keywords: $\mathrm{ZnO}$; carbon nitride; $\mathrm{ZnO} /$ carbon nitride nanocomposites; hydrothermal; photocatalysts

\section{Introduction}

In the modern world, consumption of non-renewable fossil fuels by the growing human population is resulting in a rapid depletion of fuels and ecological pollution at a frightening rate [1,2]. Currently, water pollution is highlighted as a vital concern for human beings, as it is frequently being influenced by numerous toxic pollutants such as textiles, cosmetics, food, and paint industries [3,4]. In this regard, there are several techniques available for handling polluted water, visible-light-based photocatalysis is considered to be a green approach and has fascinated globally owing to its inexhaustible solar energy [5-7]. Typically, photocatalytic features are generally ruled by its inherent physicochemical natures of materials, including its band-gap position, surface area, pore size, and morphological structures [8-11] Until now, the existing photocatalytic semiconductors such as the metal oxides and 
sulfides, oxynitrides, polymers, and organic metal complexes have been demonstrated to possess effective photocatalytic features. Among these, semiconductor metal oxides, such as $\mathrm{ZnO}, \mathrm{TiO}_{2}$, $\mathrm{Cu}_{2} \mathrm{O}, \mathrm{CuO}, \mathrm{NiO}, \mathrm{BiVO}_{4}, \mathrm{WO}_{3}$, and $\mathrm{ZnO}$, have the efficiency to maximize the absorption of incident photons [12-14]. More importantly, wider band-gap semiconductor materials such as $\mathrm{TiO}_{2}, \mathrm{ZnO}$, and $\mathrm{SrTiO}_{3}$ are already recognized as effective photocatalytic materials due to its great redox potential of photoinduced charge carriers $[15,16]$. In recent years, n-type $\mathrm{ZnO}$ semiconductors are preferred, due to its low cost, eco-friendly, simple synthetic procedure, and wide bandgap with comparison to $\mathrm{TiO}_{2}$. Particularly, the photocatalytic performance of $\mathrm{ZnO}$ was comparatively better than $\mathrm{TiO}_{2}$ in few reports. For instance, Sakthivel et al., also reported visible-light assisted photodegradation of azo dye: competition of photocatalytic efficiency [17]. However, $\mathrm{ZnO}$ or other single metal-based materials mostly suffered from photocorrosion and have average performance. On this regard, few scientific efforts are now dedicated to finding suitable approaches for decreasing the recombination rate of charge carriers working under VLI $[18,19]$.

In recent years, various reports are carried out to promote the PCA employing conventional several supporting candidates which can haste an efficient separation of photoinduced charge carriers, namely semiconductors, graphene, CNT, and other carbonaceous materials. In particular, Vadivel et al. reported the $\mathrm{BiPO}_{4} /$ multi-walled carbon nanotubes (MWCNTs) composites for the photocatalyst and supercapacitor applications [20]. Similarly, the fabrication of graphene and MWCNTs supported materials are economically expensive and produce toxicity during functionalization [21]. To solve the problems, the researcher introduced polymeric g-CN materials incorporates with semiconductor materials. More importantly, g-CN is used to improve the electron-hole pair recombination rate, stable, inexpensive, proper band position, low-cost characteristic, easily separable, unique properties, and also examined as the visible-light active materials [22-25]. The $\mathrm{CN}$ photocatalyst materials possessing conjugated electronic alignment with the band-gap of nearly $2.7 \mathrm{eV}$, holds greater thermal, chemical, electro-optical properties [26,27]. During the past decades, Wang et al. demonstrated the polymeric g-CN photocatalytic materials for a visible-light-assisted water-splitting reaction [28]. The metal-free $\mathrm{g}-\mathrm{CN}$ is restricted by lower photocatalytic activity due to fast charge recombination. Afterward, Pragati et al., studied the degradation of methylene blue (MB) using $\mathrm{ZnO} / \mathrm{g}-\mathrm{CN}$ as a photocatalyst, urea carbon source [29].

The metal-free g-CN can be fabricated by the direct pyrolysis of different organic precursors. The commercially accessible urea and thiourea were recognized as green organic precursors for the fabrication of g-CN. It was evidenced that the usage of urea and thiourea might evolve $\mathrm{CO}_{2}, \mathrm{H}_{2} \mathrm{~S}$, $\mathrm{NH}_{3}$, and $\mathrm{H}_{2} \mathrm{O}$ vapor during the pyrolysis process [30], which can be employed as a bubble soft template. Also, g-CN with the enriched surface area was fabricated by annealing both precursors of urea and thiourea, which were recrystallized in ethanol. More importantly, Zhang et al. revealed that the fabricated g-CN with the mixture of thiourea and urea exhibits the greater specific surface area and enhanced PCA compared to g-CN derivatives from the mixture of urea and thiourea [31]. Also, numerous research efforts have been found for homogeneous carbon sources like urea, melamine, formaldehyde resin and thioureas derived graphitic carbon and are incorporated with semiconductor nanoparticle [32-34]. Numerous g-CN-based heterojunctions photocatalysts have been developed by coupling g-CN with different inorganic photocatalysts [35-43]. For instance, effective combinations of catalysts comprise heterojunctions of graphene/g-CN, Au/g-CN, $\mathrm{TiO}_{2} / \mathrm{g}-\mathrm{CN}, \mathrm{MoS}_{2} / \mathrm{g}-\mathrm{CN}, \mathrm{TaON} / \mathrm{g}-\mathrm{CN}$, $\mathrm{ZnO} / \mathrm{g}-\mathrm{CN}, \mathrm{Bi}_{2} \mathrm{WO}_{6} / \mathrm{g}-\mathrm{CN}, \mathrm{CdS} / \mathrm{g}-\mathrm{CN}, \mathrm{WO}_{3} / \mathrm{g}-\mathrm{CN}$, and $\mathrm{BiOBr} / \mathrm{g}-\mathrm{CN}$ [35-43].

The PCA of $\mathrm{ZnO}$ is restricted owing to its wider bandgap and photoinduced charge carriers are easy to recombine. Also, the incorporation of various metal ions onto $\mathrm{ZnO}$ photocatalysts can efficiently enhance PCA [44-48]. Recently, doped ZnO-based photocatalysts have been demonstrated improved photocatalytic features for MB degradation [49]. Similarly, it is also revealed that the stability and PCA of $\mathrm{ZnO}$ can be promoted by loading with carbonaceous materials. Recently, Raghavan et al. fabricated a reduced graphene oxide $(\mathrm{rGO}) / \mathrm{TiO}_{2} / \mathrm{ZnO}$ system via a two-step solvothermal process [50]. Tien et al. demonstrated a hybrid photocatalyst composed of rGO and $\mathrm{ZnO}$ spheres by an easy and 
rapid microwave-assisted solvothermal reaction [51]. The formation of heterojunctions between $\mathrm{ZnO}$ and g-CN has the potential to develop efficient materials for photocatalytic applications. In this regard, it is imperious to synthesize a different variety of carbon sources to fabricate polymeric g-CN catalysts by a simple and cost-effective method. Hence, in this work, we have fabricated g-CN-based materials derived from the mixture of urea/thiourea.

Herein, $\mathrm{ZnO} / \mathrm{g}-\mathrm{CN}$ nanocomposites were fabricated by a simple and cost-efficient deposition-precipitation method, and its catalytic activity was investigated through photodegradation of MB. The graphitic $\mathrm{CN}$ was prepared by urea and thiourea mixture using the pyrolysis method. More importantly, $\mathrm{ZnO} / \mathrm{CN}$ nanocomposite shows excellent activity in as than its corresponding pristine $\mathrm{ZnO}$ and g-CN. Because of the type-II band position of $\mathrm{ZnO}$ and g-CN, the interface between g-CN and $\mathrm{ZnO}$ benefits the rapid transport of photoinduced charge carriers, thus influenced $\mathrm{ZnO} / \mathrm{CN}$ to be efficient photocatalysts. More importantly, photostability and reusability of fabricated composites investigation were also completed to identify the reactive species and explore the stability and reusability of composite materials for long time use. Lastly, a feasible photodegradation mechanism of MB above synthesized $\mathrm{ZnO} / \mathrm{g}-\mathrm{CN}$ nanocomposites has also been proposed.

\section{Experimental Details}

\subsection{Materials}

Zinc Sulfate (99.5\%), sodium hydroxide (98\%), and ethanol (99\%) were purchased from SRL chemicals (Mumbai, India). Urea (99.5\%) and thiourea (99\%) were purchased from Nice Chemicals (P) Ltd. (Ernakulam, India), MB dye was purchased from Loba Chemie (P) Ltd. (Mumbai, India).

\subsection{Preparation of g-CN/Zn Ophotocatalyst}

The $\mathrm{g}-\mathrm{CN}$ was fabricated via a pyrolysis method in which $6 \mathrm{~g}$ of urea and $6 \mathrm{~g}$ of thiourea were taken in two different $100 \mathrm{~mL}$ beakers and dissolved in $20 \mathrm{~mL}$ of deionized water [4]. Afterward, the prepared solution of urea and thiourea were mixed and then dried in an oven at around $80^{\circ} \mathrm{C}$. After which the dried reaction mixture is transferred into a crucible and heated at $550{ }^{\circ} \mathrm{C}$ for $5 \mathrm{~h}$ with the heating rate of $15^{\circ} \mathrm{C} / \mathrm{min}$. Subsequently, the attained g-CN metal-free heterojunction photocatalysts were obtained. To prepare g-CN/ZnO nanocomposites were fabricated by a simple hydrothermal process. Typically, $50 \mathrm{~mL}$ of $\mathrm{ZnSO}_{4} \cdot 7 \mathrm{H}_{2} \mathrm{O}(0.05$ moles, $0.72 \mathrm{~g})$ solution were taken in a $100-\mathrm{mL}$ beaker, and then an appropriate quantity of g-CN was dispersed using a sonicator. To prepare different nanocomposites, the amount of $\mathrm{ZnO}$ contents in $\mathrm{g}-\mathrm{CN} / \mathrm{ZnO}$ composites were varied from 60 to $75 \mathrm{wt} . \%$. Further, $50 \mathrm{~mL}$ of $\mathrm{NaOH}(1.0 \mathrm{M}, 2 \mathrm{~g})$ solution was introduced under magnetic stirring. Subsequently, the whole reaction mixture was moved to stainless-steel autoclave and kept in oven $180^{\circ} \mathrm{C}$ for $12 \mathrm{~h}$. After the hydrothermal process, the attained precipitate was then filtered and washed about 3-4 times and then dried around $60^{\circ} \mathrm{C}$ for $24 \mathrm{~h}$. The similar procedure used to prepare other composites viz., $\mathrm{g}$-CN/ZnO 60, 65, 70, and $75 \mathrm{wt} . \%$ of $\mathrm{ZnO}$ materials. According to this method, bare-ZnO was also prepared through the same hydrothermal process.

\subsection{Materials Characterization}

The phase purity and crystalline nature of g-CN/ZnO nanocomposites were collected and analyzed by using XRD techniques (Rigaku ULTIMA 1V IR-Technology service Pvt. Ltd., Tokyo, Japan). The surface functional group and introduction of the $\mathrm{ZnO}$ onto the surface of $\mathrm{g}-\mathrm{CN}$ were studied using FT-IR on a Cary 630 FT-IR Agilent Technologies India Pvt. Ltd., United States. The surface morphology and size of the $\mathrm{g}-\mathrm{CN}, \mathrm{ZnO}$ and its composites were used to study field emission scanning electron microscope (FE-SEM) Carl Zeiss: Sigma, Germany. A high-resolution transmission electron microscope (HR-TEM) was performed on a JEOL: JEM2100 PLUS, Tokyo, Japan operating at $200 \mathrm{kV}$. The photocatalytic performance of the $\mathrm{g}-\mathrm{CN}, \mathrm{ZnO}$, and its composites were studied using UV-Vis spectroscopy (Shimadzu, Model UV-3600, Kyoto, Japan). 


\subsection{Photocatalytic Study}

PCA of the fabricated photocatalytic materials was examined by the degradation of MB solution under VLI. The photocatalyst solution was prepared by the addition of $0.1 \mathrm{~g}$ of catalyst into a $100 \mathrm{~mL}$ MB $(50 \mathrm{mg} / \mathrm{L})$ solution irradiation. Initially, a sorption balance has been achieved between the MB solution and catalyst after stirring $60 \mathrm{~min}$ without VLI. After that, the prepared photocatalyst solutions were treated with VLI with a $500 \mathrm{~W}$ Xe Lamp, where the UV-light $(\lambda<420)$ had been prevented by a cut off filter. At a particular time interval, $0.2 \mathrm{~mL}$ of solution was withdrawn and then centrifuged to eliminate the catalyst particles. The absorption concentrations of the MB dye solution were spectrophotometrically observed by assessing the absorbance of solutions at $664 \mathrm{~nm}$ during the degradation process at numerous time intervals. The absorbance maximum at $\lambda=664 \mathrm{~nm}$ was employed to estimate the concentration of the MB dye solution. The photodegradation of dye is conveyed by $C / C_{0}$; Where $C_{0}$ is the residual concentration of $M B$, and $C$ is the primary concentration of the MB.

\section{Results and Discussion}

XRD analysis was used to assess the phase purity and crystalline nature of the fabricated samples. Figure 1a shows the powder XRD patterns of the prepared bare- $\mathrm{ZnO}, \mathrm{g}-\mathrm{CN}$, and a series of g-CN/ZnO nanocomposites. As seen from Figure $1 \mathrm{a}$, observed peaks at $31.8^{\circ}, 34.43^{\circ}, 36.27^{\circ}, 47.57^{\circ}, 56.67^{\circ}, 62.93^{\circ}$, $67.99^{\circ}$, and $69.20^{\circ}$ and the corresponding diffraction plans from (100), (002), (101), (102), (110), (103), (112), and (201) planes clearly indicated that hexagonal wurtzite crystal phase of ZnO (JCPDS card \# 89-0510) [12]. Also, the powdered XRD patterns of $\mathrm{ZnO}$ particles display the peak of $\mathrm{Zn}(\mathrm{OH})_{2}$ (Figure 1a). Particularly, the pure g-CN sample has two distinct peaks at $2 \theta=13.34^{\circ}$ and $27.38^{\circ}$ which can be related to (100) and (002) diffraction planes (JCPDS No. 87-1526) [22]. Also, the peak positioned at $13.34^{\circ}$ related to the in-plane packing motif (100) peak of tristriazine units. In particular, the distance is estimated to be $0.675 \mathrm{~nm}$, which is agreed to the hole-to-hole distance in the nitride pores. Simultaneously, another intense peak of $27.38^{\circ}$ is related to $\mathrm{C}-\mathrm{N}$ aromatic stacking units with a distance of $0.324 \mathrm{~nm}$, attributing to the (002) plane of the interlayer stacking of the conjugated aromatic system. In this regard, the sharp and intense diffraction peaks of both g-CN and $\mathrm{ZnO}$ evidenced their crystallinity nature. In fabricated composites, all the series of $\mathrm{g}-\mathrm{CN} / \mathrm{ZnO}$ nanocomposites shows the identical distinctive diffraction peaks with the bare- $\mathrm{ZnO}$. With the $\mathrm{ZnO}$ incorporation over the $\mathrm{g}-\mathrm{CN}$, the $\mathrm{ZnO}$ crystalline peaks appeared at $\mathrm{g}-\mathrm{CN} / \mathrm{ZnO}$ composites. There is no impurity found in the g-CN/ZnO composites, thus confirmed the successfully prepared high purity of g-CN and g-CN/ZnO nanocomposites. Further, the average particle size of the $\mathrm{ZnO}$ particles was used to calculate Scherrer's equation, the obtained particle size was $40 \pm 2 \mathrm{~nm}$. These results revealed that the $\mathrm{ZnO}$ fabricated onto $\mathrm{g}-\mathrm{CN}$ with the chemical bonding of $\mathrm{Zn}-\mathrm{N}$ was successfully achieved via condensation reactions.

Figure $1 \mathrm{~b}$ shows the FT-IR spectra of $\mathrm{ZnO}, \mathrm{g}-\mathrm{CN}$, and a series of g-CN/ZnO photocatalysts with different $\mathrm{ZnO}$ contents. FT-IR spectra of g-CN showed the following characteristic bands; $\mathrm{C}-\mathrm{N}$ stretching vibration mode at the wavenumber of $1628 \mathrm{~cm}^{-1}$ and the aromatic $\mathrm{C}-\mathrm{N}$ stretching modes are observed at 1230, 1398, and $1543 \mathrm{~cm}^{-1}$ [52]. Also, the band witnessed at $802 \mathrm{~cm}^{-1}$ is credited to out-of-plane bending modes of $\mathrm{C}-\mathrm{N}$ heterocycles [53]. More importantly, the FT-IR spectrum of independent- $\mathrm{ZnO}$, the peak located at $591 \mathrm{~cm}^{-1}$ was assigned to the stretching vibration of $\mathrm{Zn}-\mathrm{O}$ [53]. Further, a broad absorption peak positioned at $3500 \mathrm{~cm}^{-1}$ was owing to the existence of water molecules [54]. More importantly, Figure $1 \mathrm{~b}$ also displays the FT-IR spectra of a series of $\mathrm{ZnO} / \mathrm{g}-\mathrm{CN}$ composite materials, the observed peaks are identical to those of peaks of $\mathrm{g}-\mathrm{CN}$ are observed in the composite. However, with the increase in the percentage of $\mathrm{ZnO}(60 \%$ to $75 \%)$, the peak intensity also increased. Also, it is evidenced that the obtained peaks correspond to the g-CN and $\mathrm{ZnO}$ are witnessed in the g-CN/ZnO composite materials. All results have shown that the fabricated materials were nanocomposite rather than a physical combination of two distinct phases $\mathrm{ZnO}$ and g-CN. 

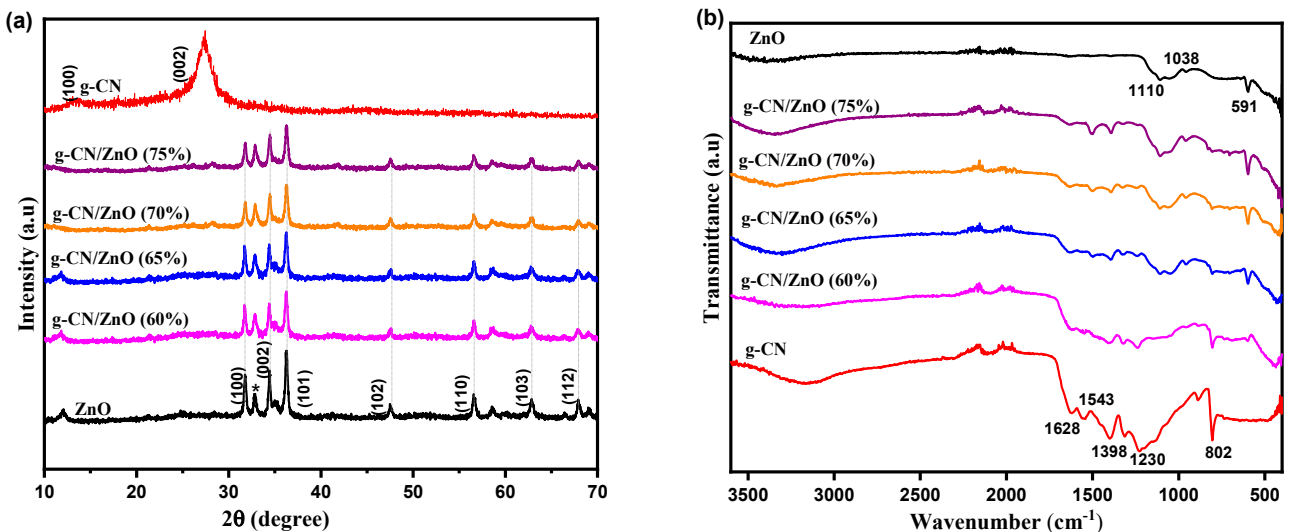

Figure 1. (a) XRD pattern of g-CN, $\mathrm{ZnO}, \mathrm{g}-\mathrm{CN} / \mathrm{ZnO}(60 \%)$, g-CN/ZnO (65\%), g-CN/ZnO (70\%), and g-CN/ZnO (75\%). The Powdered XRD pattern for composite corresponds to pure $\mathrm{ZnO}$ (wurtzite); (b) and its corresponding Fourier transform infrared (FT-IR) spectra of fabricated materials.

The surface morphology and microstructure of the g-CN, $\mathrm{ZnO}$ and g-CN/ZnO (75\%) composites were inspected through FE-SEM as presented in Figure 2. Figure 2a shows the FE-SEM images of g-CN which is composed of nanosheets sheets like structures and fluffier. Also, hydrothermally fabricated $\mathrm{ZnO}$ particles are obtained with an irregularly aggregated spherical particle (Figure 2b). Interestingly, the surface morphology of fabricated g-CN/ZnO (75\%) composites (Figure 2c,d) contains both spherical $\mathrm{ZnO}$ particles and nanosheet morphologies, which were homogeneously dispersed. Thus the fabricated binary nanocomposites materials are expected to play a vital role in determining its photocatalytic performances.

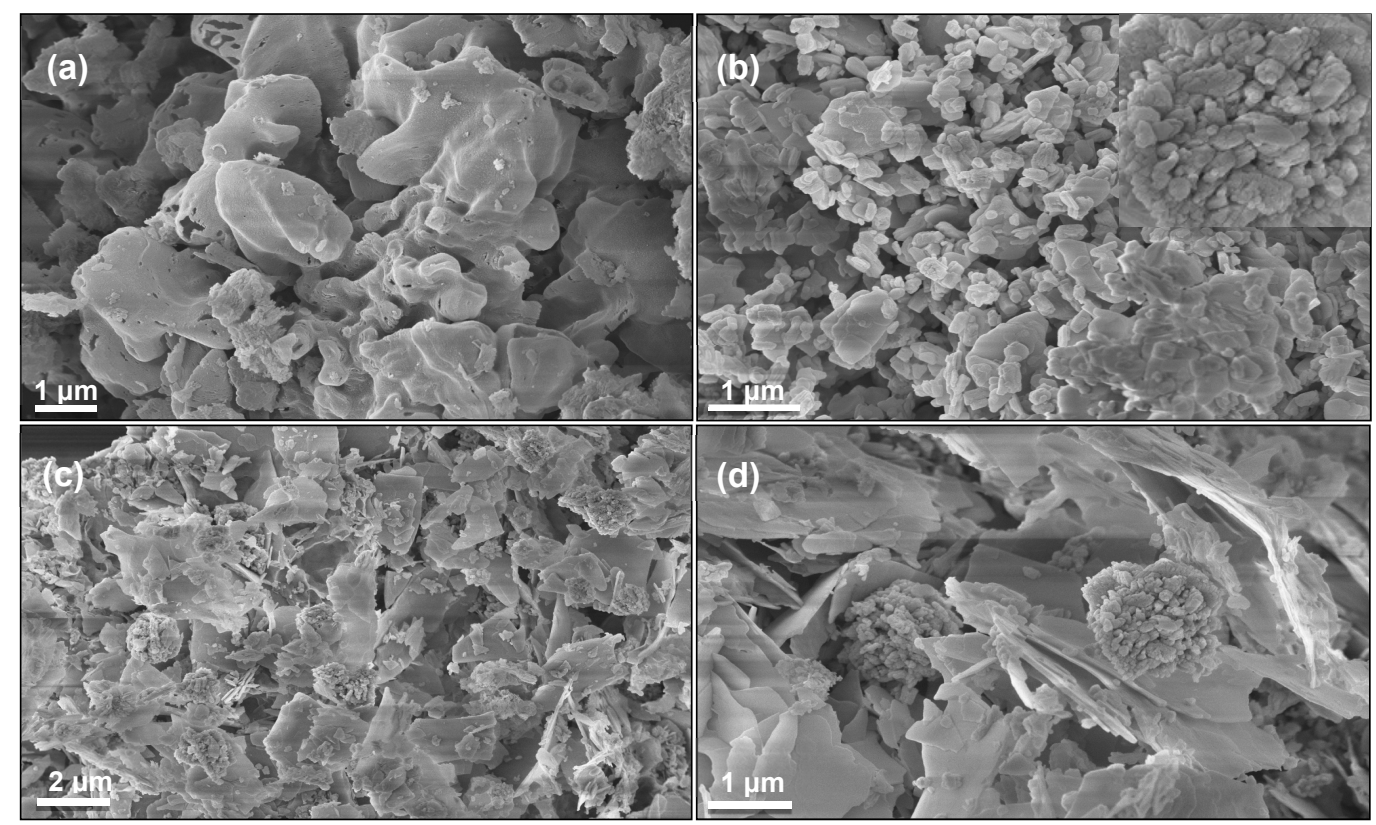

Figure 2. Field emission scanning electron microscope (FE-SEM) image of: (a) g-CN, (b) bare-ZnO, and $(\mathbf{c}, \mathrm{d}) \mathrm{g}-\mathrm{CN} / \mathrm{ZnO}(75 \%)$ composite materials prepared using a hydrothermal process.

To further assess the morphological features of fabricated composites, the HR-TEM measurements were carried out and are depicted in Figure 3. HR-TEM images of g-CN/ZnO (75\%) composite as seen in Figure 3a,b, clearly observed the darker particles of $\mathrm{ZnO}$ over the thin layer sheets of g-CN, which is consistent with FE-SEM analysis. Furthermore, HR-TEM of a composite at higher magnifications to observe more number of fringe patterns of $\mathrm{ZnO}$ particles over g-CN sheets (Figure 3c,d). The observed 
interplanar distance (d) of $0.252 \mathrm{~nm}$ is observed to have matched with the lattice fringe spacing of the (101) $\mathrm{ZnO}$ hexagonal wurtzite phase, which also reveals the interface between the hexagonal $\mathrm{ZnO}$ and g-CN sheets [12]. Inset of Figure $3 \mathrm{~d}$ reveals the respective selected area electron diffraction (SAED) pattern of g-CN. These morphological investigations evidenced the interface between g-CN nanosheets and $\mathrm{ZnO}$ particles in the composites and are appropriate candidate materials to enhance the charge-separation and thereby enhancement of the PCA.

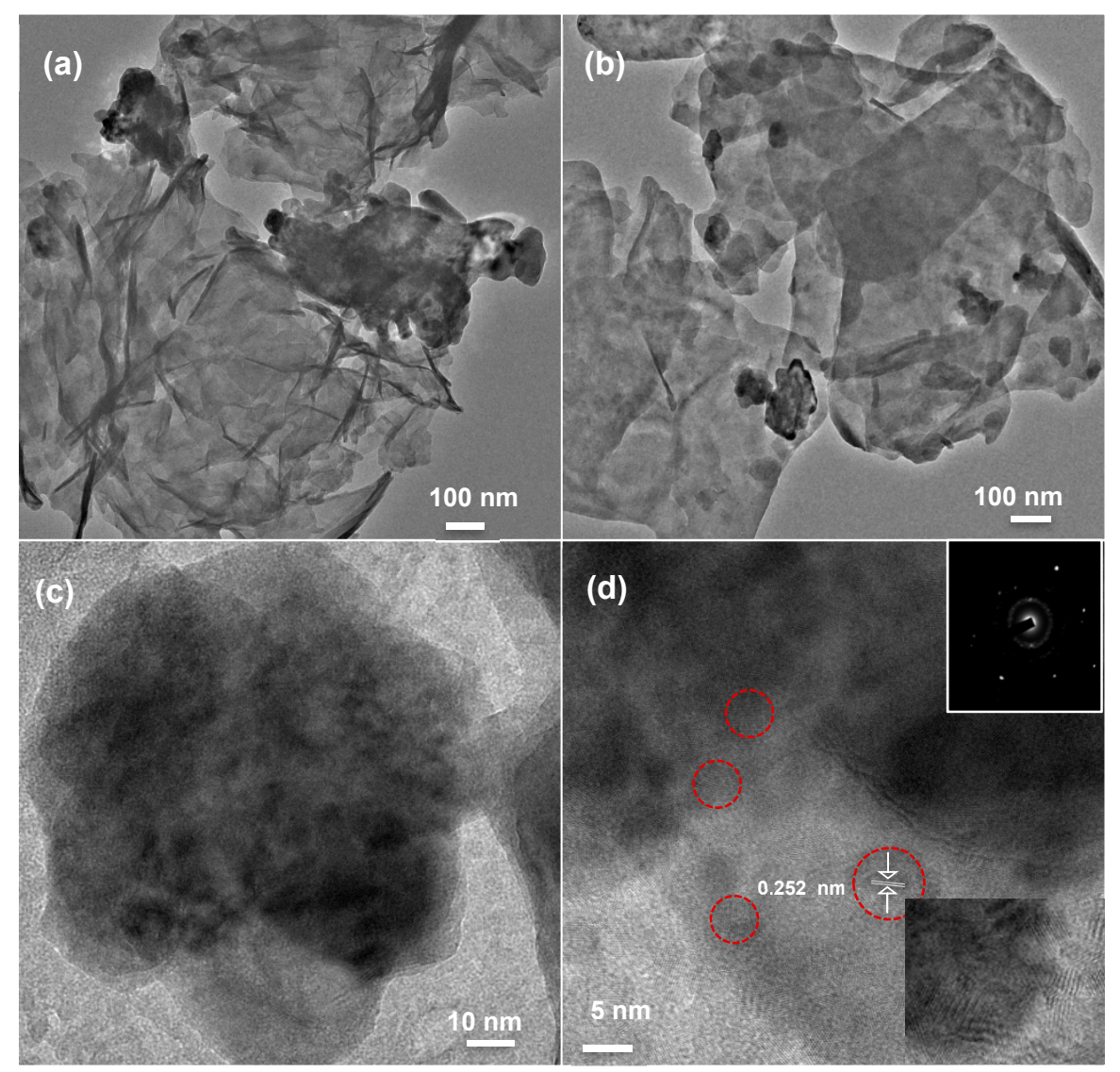

Figure 3. High-resolution transmission electron microscope (HR-TEM) images of: (a,b) g-CN/ZnO (75\%) (low magnification), (c,d) g-CN/ZnO (75\%) (high magnification), and the inset shows the diffraction pattern of $\mathrm{CN} / \mathrm{ZnO}(75 \%)$.

\subsection{Photocatalytic Activity}

The photocatalytic $\mathrm{MB}$ dye degradation performances of $\mathrm{ZnO}$ and g-CN/ZnO photocatalyst were studied under VLI. In a typical process, the maximum absorption concentration MB dye peak at 664 $\mathrm{nm}$ was taken to investigate the catalytic degradation of MB dye. Particularly, the time-dependent absorption spectra of MB with differently prepared photocatalysts were displayed in Figure 4 . The maximum absorption intensity $\mathrm{MB}$ dye was slowly decreased in the presence of pristine $\mathrm{ZnO}$ with the illumination of VLI. The observed result clearly shows the low degradation efficiency of pristine $\mathrm{ZnO}$ nanoparticles (Figure 4a). Moreover, after the addition of g-CN into the $\mathrm{ZnO}$ nanoparticles, the catalytic activity was gradually increased which means the g-CN nanosheets are influenced toward the enhanced PCA. Interestingly, the photodegradation efficiency of the g-CN/ZnO $(75 \%)$ photocatalysts was considerably greater than that of pristine $\mathrm{ZnO}$ and other combinations of g-CN/ZnO. Amongst all the as-prepared samples, g-CN/ZnO (75\%) exhibited improved catalytic activity because of the enhanced visible-light absorption and suppressed recombination rate in comparison with bare $\mathrm{ZnO}$ photocatalyst or g-CN. Similarly, g-CN provided more active surface and strong absorption capacity to MB dye molecules. Furthermore, the layered nanosheets structure of g-CN favored the 
photogenerated electron-hole transfer from g-CN to $\mathrm{ZnO}$. It is a significant factor in photocatalytic activities of $\mathrm{g}-\mathrm{CN} / \mathrm{ZnO}(75 \%)$ nanocomposites as photocatalysts.
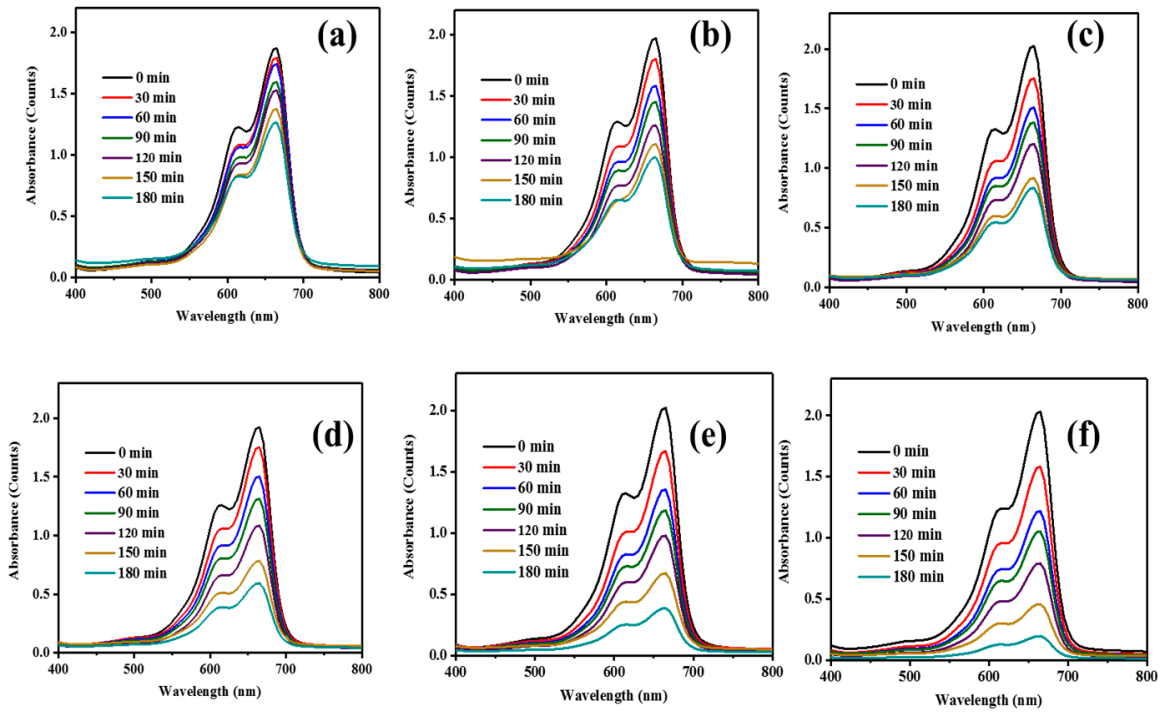

Figure 4. UV-Vis absorbance spectra of visible-light degradation of methylene blue (MB) dye in the presence of (a) bare-ZnO, (b) undoped g-CN, (c) g-CN/ZnO (60\%), (d) g-CN/ZnO (65\%), (e) g-CN/ZnO $(70 \%)$, and (f) g-CN/ZnO (75\%).

Figure 5 reveals the photodegradation of $\mathrm{MB}$ over bare- $\mathrm{ZnO}$, undoped $\mathrm{g}-\mathrm{CN}$, and a series of g-CN/ZnO composites. The blank analysis was performed without a catalyst to determine the stability of $\mathrm{MB}$ under illumination conditions and the results indicated that the $\mathrm{MB}$ was stable under illumination. Figure 5 shows the kinetic plot of $\left(\mathrm{C}_{0} / \mathrm{C}_{\mathrm{t}}\right)$ vs. irradiation time $(\mathrm{min})$ to examine the degradation of $\mathrm{MB}$ dye in the presence of as-prepared catalysts.

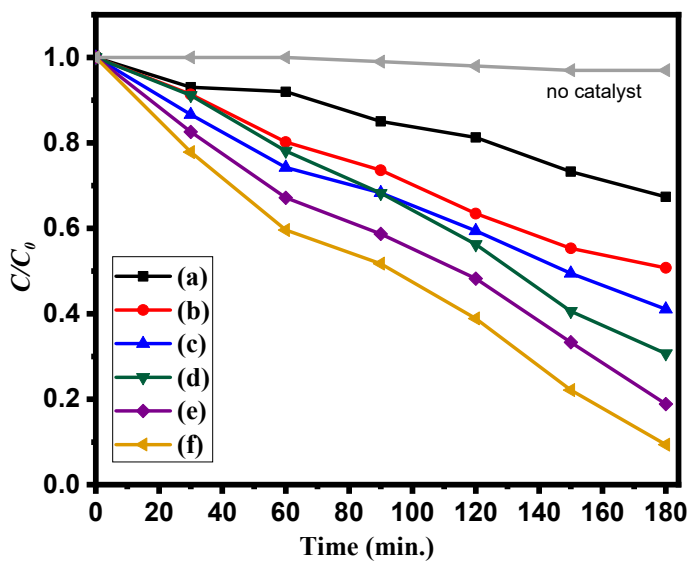

Figure 5. Photodegradation of $\mathrm{MB}$ dye over the presence of: (a) bare- $\mathrm{ZnO}$, (b) undoped g-CN, (c) g-CN/ZnO (60\%), (d) g-CN/ZnO (65\%), (e) g-CN/ZnO (70\%), and (f) g-CN/ZnO (75\%).

Further, to understand the reaction kinetics of the MB degradation catalyzed by fabricated catalysts, the experimental data were fitted by a first-order kinetic model as shown by following Equation (1):

$$
\ln \left(\mathrm{C}_{0} / \mathrm{C}\right)=\mathrm{kt}
$$

where $\mathrm{C}_{0}$ and $\mathrm{C}$ are the initial and concentration of $\mathrm{MB}$ at a certain time interval and $k$ is the rate constant. Figure 6 shows the linear fitting kinetic plot for the degradation of MB for fabricated catalysts. 
The observed results clearly show that the prepared catalyst obeyed the pseudo-first-order kinetics. The calculated rate constants $\left(K_{\text {app }}\right)$, agreeing with correlation coefficients $\left(R^{2}\right)$, and maximal dye degradation in the presence of pristine and g- $\mathrm{CN} / \mathrm{ZnO}$ nanocomposites are given Table 1 . The estimated $k$ values for the bare $\mathrm{ZnO}$, bare g-CN, g-CN/ZnO (60\%), g-CN/ZnO (70\%), and g-CN/ZnO (75\%) are found to be $0.0021,0.0038,0.0047,0.009$, and $0.0128 \mathrm{~min}^{-1}$, correspondingly. Also, it is demonstrated that $\mathrm{g}-\mathrm{CN} / \mathrm{ZnO}(75 \%)$ composite has a greater rate constant which was $\sim 6$-folds superior to the bare $\mathrm{ZnO}$. The existence of more reacting species, larger surface area, and enriched acting sites are improving the PCA. More importantly, the observed rate constant value also larger than that obtained for Fe-doped $\mathrm{ZnO}$ as reported by Isai et al [55] and larger with that observed for boron-doped g-CN-based composite [56].

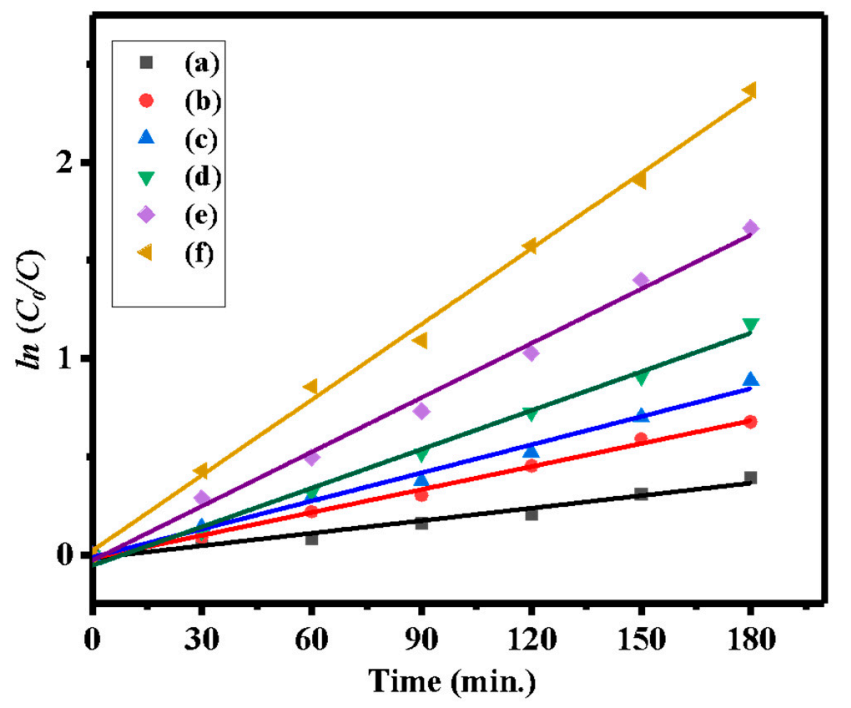

Figure 6. Pseudo-first-order kinetic plots of: (a) bare $\mathrm{ZnO}$, (b) bare g-CN, (c) g-CN/ZnO (60\%), (d) g-CN/ZnO(65\%), (e) g-CN/ZnO (70\%), and (f) g-CN/ZnO (75\%).

Table 1. Data obtained from a pseudo-first-order kinetic linear fit of as-prepared catalyst.

\begin{tabular}{ccccccc}
\hline \multirow{2}{*}{ Sample } & Bare ZnO & Bare g-CN & $\begin{array}{c}\text { g-CN/ZnO } \\
\mathbf{( 6 0 \% )}\end{array}$ & $\begin{array}{c}\text { g-CN/ZnO } \\
\mathbf{( 6 5 \% )}\end{array}$ & $\begin{array}{c}\text { g-CN/ZnO } \\
\mathbf{( 7 0 \% )}\end{array}$ & $\begin{array}{c}\text { g-CN/ZnO } \\
(\mathbf{7 5} \% \mathbf{)}\end{array}$ \\
\hline \multirow{2}{*}{ Intercept } & $-0.0155 \pm$ & $-0.0159 \pm$ & $-0.010 \pm$ & $-0.0532 \pm$ & $-0.027 \pm 0.03$ & $0.0217 \pm$ \\
& 0.018 & 0.012 & 0.023 & 0.026 & 0.038 \\
\hline Rate & $0.0021 \pm$ & $0.00389 \pm$ & $0.00477 \pm$ & $0.00658 \pm$ & $0.00922 \pm$ & $0.01283 \pm$ \\
Constant & 0.00017 & 0.000119 & 0.00021 & 0.000242 & 0.0003295 & 0.0003542 \\
\hline R-Square & 0.96877 & 0.99535 & 0.99045 & 0.99328 & 0.99365 & 0.9962 \\
\hline
\end{tabular}

Figure 7 shows the photodegradation efficiency of as-prepared nanocomposite samples in comparison with bare samples. The bare $\mathrm{ZnO}$, bare g-CN, g-CN/ZnO (60\%), g-CN/ZnO (65\%), g-CN/ZnO (70\%), and g-CN/ZnO (75\%) materials are found to degrade around $26 \%, 45 \%, 60 \%, 69 \%$, $80 \%$, and $91 \%$ the MB solution under 120 min of irradiation. These results evidenced that with an increase in the amount of $\mathrm{ZnO}$ into the g-CN the PCA also gradually increased. The observed degradation result confirms that the $\mathrm{g}-\mathrm{C}_{3} \mathrm{~N}_{4}$ prominently improve the PCA. 


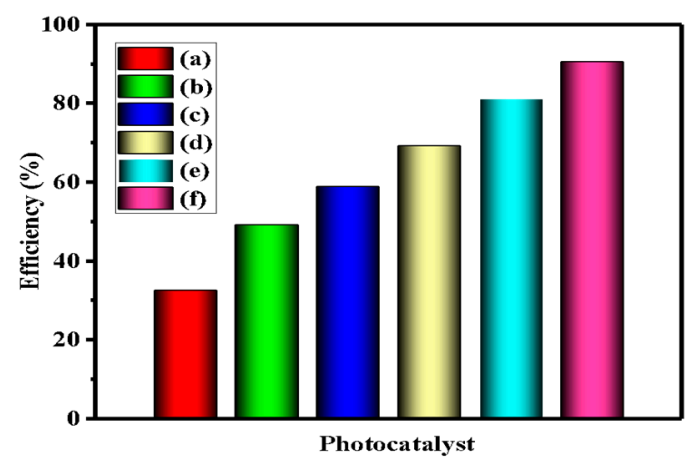

Figure 7. $\mathrm{MB}$ dye degradation efficiency of as-prepared catalysts: (a) bare- $\mathrm{ZnO}$, (b) undoped g-CN, (c) g-CN/ZnO (60\%), (d) g-CN/ZnO(65\%), (e) g-CN/ZnO (70\%), and (f) g-CN/ZnO (75\%).

\subsection{Reactive Species Studies}

To know the role of active species in the MB dye degradation activity, radical trapping tests were performed, as displayed in Figure 8. The close inter-phase contact coupling of g-CN and $\mathrm{ZnO}$ particles in g-CN/ZnO must play a major part in improving PCA [39,57]. In general, the close coupling of $\mathrm{ZnO} / \mathrm{g}-\mathrm{Cn}$ nanoparticles results in promoting the electron transfer between interfaces and hindering the recombination of photoinduced charge carriers [58]. Usually, during the photocatalysis process, hydroxyl, holes, and superoxide radicals are the promising reactive species for the degradation of organic pollutants [59]. Herein, isopropyl alcohol (IPA), triethanolamine (TEOA), and p-benzoquinone (BQ) which are engaged as the scavengers for hydroxyl, holes, and superoxide radicals, correspondingly [12]. In a scavenger free reaction, the MB dye maximum degradation efficiency was observed up to $90.64 \%$ in $180 \mathrm{~min}$ irradiation for g-CN/ZnO (75\%). So the g-CN/ZnO (75\%) samples were selected to investigate the radical trapping study. After the introduction of radical trapping agents into the photocatalytic reaction, the degradation efficiency was decreased particularly, the observed efficiency was 90.6, 42.1, 76.3 , and 62.9 percentages for without scavenger, TEOA, BQ, and IPA, respectively. This investigation confirmed that hole played a major role in the photocatalytic MB degradation compared to other radicals which means that after the addition of TEOA into the reaction nearly $60 \%$ of the efficiency was hindered. Hence, these results show that MB degradation mainly is governed by photogenerated holes.

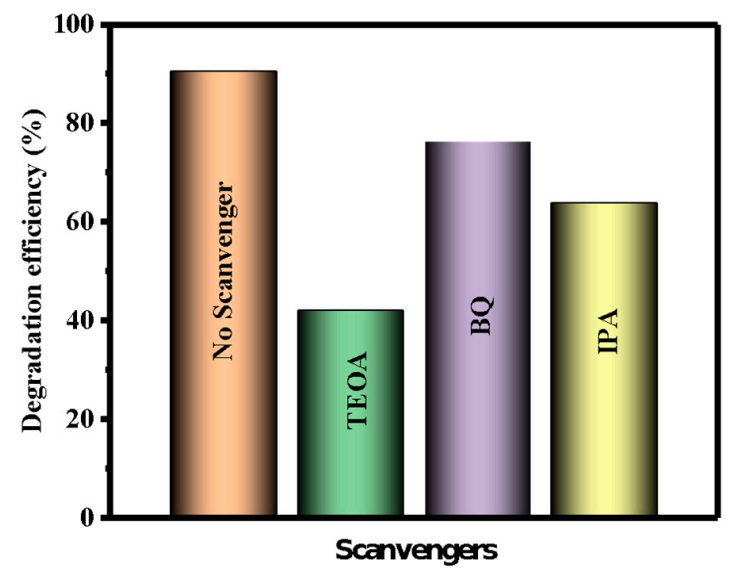

Figure 8. Influence of radical scavengers for the photodegradation of $\mathrm{MB}$ on $\mathrm{g}-\mathrm{CN} / \mathrm{ZnO}(75 \%)$ nanocomposite under illumination conditions.

\subsection{Reusability Studies}

The stability of the synthesized catalyst materials was examined by recycling the photocatalysts for the photocatalytic degradation of MB dye. Each cycle, a fresh MB dye solution was used for the next photocatalytic test. The catalyst particles were collected by centrifuged and washed, with distilled 
water then reused. As shown in Figure 9, no major reduction was observed in the efficiency after four consecutive cycles, as a result, the $\mathrm{g}-\mathrm{CN} / \mathrm{ZnO}(75 \%)$ photocatalysts were photostable.

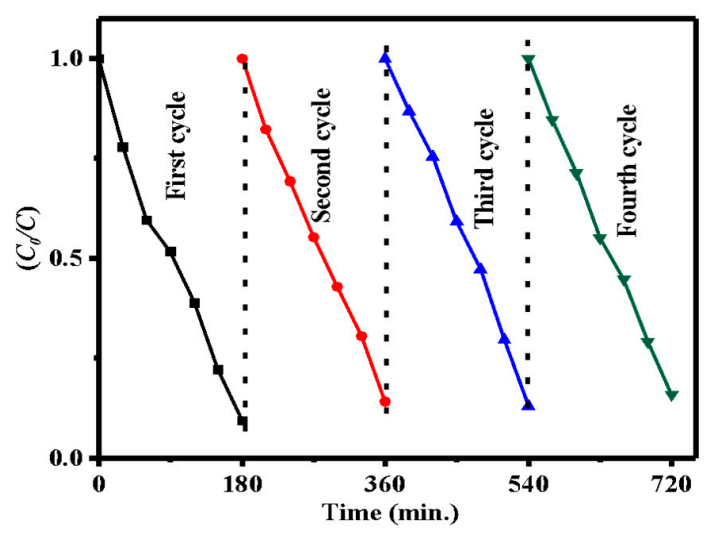

Figure 9. Recycling stability studies for the catalytic degradation of $\mathrm{MB}$ dye on $\mathrm{g}-\mathrm{CN} / \mathrm{ZnO}(75 \%)$ composites under illumination.

\subsection{Mechanism}

The apparent charge-transfer mechanism for $\mathrm{MB}$ degradation over $\mathrm{g}-\mathrm{CN} / \mathrm{ZnO}$ system was presented in Figure 10. As it is known that, the pure $\mathrm{ZnO}$ cannot be excited by visible light irradiation, the photodegradation of $\mathrm{MB}$ can mainly be attributed to the photogenerated hole oxidation and photoreduction process. On comparing pure g- $\mathrm{CN}$, the $\mathrm{g}-\mathrm{CN} / \mathrm{ZnO}$ photocatalysts exhibited remarkable enhancement for degrading $\mathrm{MB}$ under visible light. The $\mathrm{CB}$ and VB edge potentials of as-synthesized pristine $\mathrm{ZnO}$ and g-CN were acquired from Butler-Ginley method [60,61]. The CB and VB edge potentials of the g-CN were calculated to be -1.12 and $+1.57 \mathrm{eV}$, while the $\mathrm{CB}$ and $\mathrm{VB}$ edge position of $\mathrm{ZnO}$ are -0.26 and $+2.83 \mathrm{eV}$, respectively. The appropriate band positions of $\mathrm{g}-\mathrm{CN}$ and $\mathrm{ZnO}$ endorse the creation of the heterojunction and thereby improvement in PCA. According to the proposed mechanism, both $\mathrm{ZnO}$ and g-CN are expected to be photoinduced to create carriers. Under VLI conditions, since the $\mathrm{CB}$ potential of g-CN is more negative than that of $\mathrm{ZnO}$, the photogenerated electrons on g-CN particle surfaces transfer easily to $\mathrm{ZnO}$ through the well-developed interface [62]. So the excited electron on g-CN could directly inject into the $\mathrm{CB}$ of $\mathrm{ZnO}$. The electron-hole separations are also driven by the internal reassembly rebuilt electric fields in the two semiconductors. This decreases the strength of electron-hole recombination and leads to large numbers of electrons on the $\mathrm{ZnO}$ surface and holes on the g-CN surface, respectively, thus promoting the photocatalytic reactions to degradation MB.

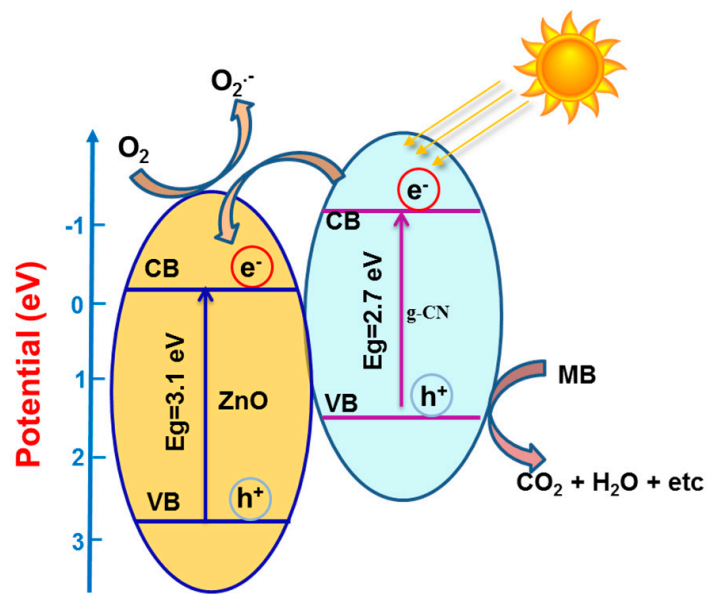

Figure 10. Proposed Z-scheme mechanism for enhanced photocatalytic features of MB over fabricated g-CN/ZnO composite under visible-light irradiation (VLI). 


\section{Conclusions}

In conclusion, we adopted a facile hydrothermal approach to produce new g-CN/ZnO composites for photocatalytic decomposition of MB under VLI. The various compositions of g-CN/ZnO composites in the range of $\mathrm{ZnO}$ from $60 \%$ to $75 \%$ were prepared. The structural analysis of the g-CN/ZnO composite was studied using XRD, FT-IR, SEM, and TEM techniques. The g-CN/ZnO composites exhibited higher PCA and an easy recycling process, but $\mathrm{ZnO}$ easily suffered photocorrosion. The main reason could be suggested that the porous nature of g-CN can effectively separate photoinduced charge carries and diminish the photocorrosion of $\mathrm{ZnO}$ and thereby extraordinarily enhance visible-light PCA for the photodegradation of pollutants. The obtained results reveal that the g-CN/ZnO (75\%) composites can effectively degrade $98 \%$ of MB dye within 180 min under UV light which is greatly superior to that of $\mathrm{ZnO}$ and g-CN. More importantly, the PCA of g-CN/ZnO under VLI was increased six times for the degradation of $\mathrm{MB}$ in comparison to bare $\mathrm{ZnO}$. In the photodegradation of $\mathrm{MB}$ by $\mathrm{g}-\mathrm{CN} / \mathrm{ZnO}$ composites, photoinduced holes are the major species. Besides, benefiting from the graphitic carbon nitride excellent supporting materials, green synthetic, cost-effective of precursors, the obtained flexible heterojunctions $\mathrm{g}-\mathrm{CN} / \mathrm{ZnO}$ composites provide very fascinating prospects and may be stretched to the applications such as adsorbents, electrochemical materials, and support for sensors.

Author Contributions: R.C.N. and P.S performed the experiments and wrote the manuscript. S.O.A., T.P., and K.B. provided suggestions and assistance in experimental design. P.S. and P.A. assisted in experimental work and manuscript editing. All authors have read and agreed to the published version of the manuscript.

Funding: This research received no external funding.

Acknowledgments: The authors gratefully acknowledged the instrumental supports from Science and Humanities, NIT Nagaland. Dr. Saleh O. Alaswad acknowledges Nuclear Science Research Institute (NSRI), King Abdulaziz City for Science and Technology (KACST) for their technical support.

Conflicts of Interest: The authors declare no conflict of interest.

\section{References}

1. Gaya, U.I.; Abdullah, A.H. Heterogeneous photocatalytic degradation of organic contaminants over titanium dioxide: A review of fundamentals, progress and problems. J. Photochem. Photobiol. C Photochem. Rev. 2008, 9, 1-12. [CrossRef]

2. Guo, F.; Cai, Y.; Guan, W.; Huang, H.; Liu, Y. Graphite carbon nitride/ZnIn $\mathrm{S}_{4}$ heterojunction photocatalyst with enhanced photocatalytic performance for degradation of tetracycline under visible light irradiation. J. Phys. Chem. Solids 2017, 110, 370-378. [CrossRef]

3. Bora, L.V.; Mewada, R.K. Visible/solar light active photocatalysts for organic effluent treatment: Fundamentals, mechanisms and parametric review. Renew. Sustain. Energy Rev. 2017, 76, 1393-1421. [CrossRef]

4. Xu, Q.; Feng, J.; Li, L.; Xiao, Q.; Wang, J. Hollow $\mathrm{ZnFe}_{2} \mathrm{O}_{4} / \mathrm{TiO}_{2}$ composites: High-performance and recyclable visible-light photocatalyst. J. Alloys Compd. 2015, 641, 110-118. [CrossRef]

5. Yu, C.; Cao, F.; Li, G.; Wei, R.; Yu, J.C.-M.; Jin, R.; Fan, Q.; Wang, C. Novel noble metal (Rh, Pd, Pt)/BiOX(Cl, $\mathrm{Br}, \mathrm{I})$ composite photocatalysts with enhanced photocatalytic performance in dye degradation. Sep. Purif. Technol. 2013, 120, 110-122. [CrossRef]

6. Yang, L.; Duan, W.; Jiang, H.; Luo, S.; Luo, Y. Mesoporous $\mathrm{TiO}_{2} @ \mathrm{Ag}_{3} \mathrm{PO}_{4}$ photocatalyst with high adsorbility and enhanced photocatalytic activity under visible light. Mater. Res. Bull. 2015, 70, 129-136. [CrossRef]

7. Nazari, M.; Golestani-Fard, F.; Bayati, R.; Eftekhari-Yekta, B. Enhanced photocatalytic activity in anodized $\mathrm{WO}_{3}$-loaded $\mathrm{TiO}_{2}$ nanotubes. Superlattices Microstruct. 2015, 80, 91-101. [CrossRef]

8. Dong, F.; Zhao, Z.; Xiong, T.; Ni, Z.; Zhang, W.; Sun, Y.; Ho, W.K. In situ construction of g- $\mathrm{C}_{3} \mathrm{~N}_{4} / \mathrm{g}-\mathrm{C}_{3} \mathrm{~N}_{4}$ metal-free heterojunction for enhanced visible-light photocatalysis. ACS Appl. Mater. Interfaces 2013, 5, 11392-11401. [CrossRef]

9. Xiang, Q.; Yu, J.; Jaroniec, M. Graphene-based semiconductor photocatalysts. Chem. Soc. Rev. 2012, 41, 782-796. [CrossRef]

10. Tong, H.; Ouyang, S.; Bi, Y.; Umezawa, N.; Oshikiri, M.; Ye, J. Nano-photocatalytic materials: Possibilities and challenges. Adv. Mater. 2012, 24, 229-251. [CrossRef] 
11. Di Paola, A.; García-López, E.; Marcì, G.; Palmisano, L. A survey of photocatalytic materials for environmental remediation. J. Hazard. Mater. 2012, 211, 3-29. [CrossRef]

12. Priya, A.; Arumugam, M.; Arunachalam, P.; Al-Mayouf, A.M.; Madhavan, J.; Theerthagiri, J.; Choi, M.Y. Fabrication of visible-light active $\mathrm{BiFeWO}_{6} / \mathrm{ZnO}$ nanocomposites with enhanced photocatalytic activity. Colloids Surf. A Physicochem. Eng. Asp. 2020, 586, 124294.

13. Theerthagiri, J.; Salla, S.; Senthil, R.A.; Nithyadharseni, P.; Madankumar, A.; Arunachalam, P.; Maiyalagan, T.; Kim, H.-S.; Jayaraman, T.; Kim, H.S.; et al. A review on ZnO nanostructured materials: Energy, environmental and biological applications. Nanotechnology 2019, 30, 392001. [CrossRef]

14. Malathi, A.; Madhavan, J.; Ashokkumar, M.; Arunachalam, P. A review on $\mathrm{BiVO}_{4}$ photocatalyst: Activity enhancement methods for solar photocatalytic applications. Appl. Catal. A Gen. 2018, 555, 47-74. [CrossRef]

15. Karthikeyan, C.; Arunachalam, P.; Ramachandran, K.; Al-Mayouf, A.M.; Karuppuchamy, S. Recent advances in semiconductor metal oxides with enhanced methods for solar photocatalytic applications. J. Alloys Compd. 2020, 828, 154281. [CrossRef]

16. Arunachalam, P.; Amer, M.S.; Ghanem, M.A.; Almayouf, A.M.; Zhao, D. Activation effect of silver nanoparticles on the photoelectrochemical performance of mesoporous $\mathrm{TiO}_{2}$ nanospheres photoanodes for water oxidation reaction. Int. J. Hydrogen Energy 2017, 42, 11346-11355. [CrossRef]

17. Sakthivel, S.; Neppolian, B.; Shankar, M.V.; Arabindoo, B.; Palanichamy, M.; Murugesan, V. Solar photocatalytic degradation of azo dye: Comparison of photocatalytic efficiency of $\mathrm{ZnO}$ and $\mathrm{TiO}_{2}$. Sol. Energy Mater. Sol. cells 2003, 77, 65-82. [CrossRef]

18. Lu, J.; Hu, H.; Yang, S.; Shanmugam, P.; Wei, W.; Selvaraj, M.; Xie, J. ZnS@carbonaceous aerogel composites fabricated in production of hydrogen and for removal of organic pollutants. J. Mater. Sci. Mater. Electron. 2018, 29, 8523-8534. [CrossRef]

19. Shi, M.; Wei, W.; Jiang, Z.; Han, H.; Gao, J.; Xie, J. Biomass-derived multifunctional $\mathrm{TiO}_{2} /$ carbonaceous aerogel composite as a highly efficient photocatalyst. RSC Adv. 2016, 6, 25255-25266. [CrossRef]

20. Vadivel, S.; Naveen, A.N.; Theerthagiri, J.; Madhavan, J.; Priya, T.S.; Balasubramanian, N. Solvothermal synthesis of BiPO4 nanorods/MWCNT (1D-1D) composite for photocatalyst and supercapacitor applications. Ceram. Int. 2016, 42, 14196-14205. [CrossRef]

21. Shanmugam, P.; Murthy, A.P.; Theerthagiri, J.; Wei, W.; Madhavan, J.; Kim, H.-S.; Maiyalagan, T.; Xie, J. Robust bifunctional catalytic activities of N-doped carbon aerogel-nickel composites for electrocatalytic hydrogen evolution and hydrogenation of nitrocompounds. Int. J. Hydrogen Energy 2019, 44, 13334-13344. [CrossRef]

22. Priya, A.; Senthil, R.A.; Selvi, A.; Arunachalam, P.; Kumar, C.S.; Madhavan, J.; Boddula, R.; Pothu, R.; Al-Mayouf, A.M. A study of photocatalytic and photoelectrochemical activity of as-synthesized WO3/g-C3N4 composite photocatalysts for AO7 degradation. Mater. Sci. Energy Technol. 2020, 3, 43-50. [CrossRef]

23. Thiagarajan, K.; Bavani, T.; Arunachalam, P.; Lee, S.J.; Theerthagiri, J.; Madhavan, J.; Pollet, B.G.; Choi, M.Y. Nanofiber $\mathrm{NiMoO}_{4} / \mathrm{g}-\mathrm{C}_{3} \mathrm{~N}_{4}$ Composite Electrode Materials for Redox Supercapacitor Applications. Nanomaterials 2020, 10, 392. [CrossRef]

24. Senthil, R.A.; Theerthagiri, J.; Madhavan, J.; Murugan, K.; Arunachalam, P.; Arof, A.K. Enhanced performance of dye-sensitized solar cells based on organic dopant incorporated PVDF-HFP/PEO polymer blend electrolyte with $\mathrm{g}_{-} \mathrm{C}_{3} \mathrm{~N}_{4} / \mathrm{TiO}_{2}$ photoanode. J. Solid State Chem. 2016, 242, 199-206. [CrossRef]

25. Wen, M.Q.; Xiong, T.; Zang, Z.G.; Wei, W.; Tang, X.S.; Dong, F. Synthesis of $\mathrm{MoS}_{2} / \mathrm{gC}_{3} \mathrm{~N}_{4}$ nanocomposites with enhanced visible-light photocatalytic activity for the removal of nitric oxide (NO). Opt. Express 2016, 24, 10205-10212. [CrossRef]

26. Zhang, X.; Xie, X.; Wang, H.; Zhang, J.; Pan, B.; Xie, Y. Enhanced photoresponsive ultrathin graphitic-phase C3N4 nanosheets for bioimaging. J. Am. Chem. Soc. 2013, 135, 18-21. [CrossRef]

27. Huang, L.; Li, Y.; Xu, H.; Xu, Y.; Xia, J.; Wang, K.; Xu, Y.; Cheng, X. Synthesis and characterization of $\mathrm{CeO}_{2} / \mathrm{gC}_{3} \mathrm{~N}_{4}$ composites with enhanced visible-light photocatatalytic activity. RSC Adv. 2013, 3, 22269-22279. [CrossRef]

28. Wang, X.; Maeda, K.; Thomas, A.; Takanabe, K.; Xin, G.; Carlsson, J.M.; Domen, K.; Antonietti, M. A metal-free polymeric photocatalyst for hydrogen production from water under visible light. Nat. Mater. 2008, 8, 76-80. [CrossRef] 
29. Fageria, P.; Nazir, R.; Gangopadhyay, S.; Barshilia, H.C.; Pande, S. Graphitic-carbon nitride support for the synthesis of shape-dependent $\mathrm{ZnO}$ and their application in visible light photocatalysts. RSC Adv. 2015, 5, 80397-80409. [CrossRef]

30. Dong, F.; Wu, L.W.; Sun, Y.J.; Fu, M.; Wu, Z.B.; Lee, S.C. In Situ Construction of g- $\mathrm{C}_{3} \mathrm{~N}_{4} / g-\mathrm{C}_{3} \mathrm{~N}_{4}$ Metal-Free Heterojunction for Enhanced Visible-Light Photocatalysis. J. Mater. Chem. 2011, 21, 15171-15174. [CrossRef]

31. Zhang, Y.; Gong, H.; Li, G.; Zeng, H.; Zhong, L.; Liu, K.; Cao, H.; Yan, H. Synthesis of graphitic carbon nitride by heating mixture of urea and thiourea for enhanced photocatalytic $\mathrm{H} 2$ production from water under visible light. Int. J. Hydrogen Energy 2017, 42, 143-151. [CrossRef]

32. Dong, F.; Sun, Y.; Wu, L.; Fu, M.; Wu, Z. Facile transformation of low cost thiourea into nitrogen-rich graphitic carbon nitride nanocatalyst with high visible light photocatalytic performance. Catal. Sci. Technol. 2012, 2, 1332-1335. [CrossRef]

33. Lu, J.; Zhang, Q.; Wang, J.; Saito, F.; Uchida, M. Synthesis of N-Doped ZnO by grinding and subsequent heating ZnO-urea mixture. Powder Technol. 2006, 162, 33-37. [CrossRef]

34. Zhang, W.; Zhang, Q.; Dong, F.; Zhao, Z. The Multiple Effects of Precursors on the Properties of Polymeric Carbon Nitride. Int. J. Photoenergy 2013, 685038. [CrossRef]

35. Xiang, Q.; Yu, J.; Jaroniec, M. Preparation and Enhanced Visible-Light Photocatalytic H2-Production Activity of Graphene/C3N4 Composites. J. Phys. Chem. C 2011, 115, 7355-7363. [CrossRef]

36. Hou, Y.D.; Laursen, A.B.; Zhang, J.S.; Zhang, G.G.; Zhu, Y.S.; Wang, X.C.S. Dahl an I. Chorkendorff. Angeww. Chem. Int. Ed. 2013, 52, 1-6.

37. Yan, H.; Yang, H. TiO2-g-C3N4 composite materials for photocatalytic H2 evolution under visible light irradiation. J. Alloys Compd. 2011, 509, L26-L29. [CrossRef]

38. Yan, S.C.; Lv, S.B.; Zou, Z.; Li, Z.S. Organic-inorganic composite photocatalyst of g-C3N4 and TaON with improved visible light photocatalytic activities. Dalton Trans. 2010, 39, 1488-1491. [CrossRef]

39. Sun, J.-X.; Yuan, Y.; Qiu, L.-G.; Jiang, X.; Shena, Y.; Shena, Y.; Zhu, J. Fabrication of composite photocatalyst g-C3N4-ZnO and enhancement of photocatalytic activity under visible light. Dalton Trans. 2012, 41, 6756-6763. [CrossRef]

40. Wang, Y.; Bai, X.; Pan, C.; He, J.; Zhu, Y. Enhancement of photocatalytic activity of Bi2WO6 hybridized with graphite-like C3N4. J. Mater. Chem. 2012, 22, 11568-11573. [CrossRef]

41. Cheng, N.; Tian, J.; Liu, Q.; Ge, C.; Qusti, A.H.; Asiri, A.M.; Al-Youbi, A.O.; Sun, X. Au-Nanoparticle-Loaded Graphitic Carbon Nitride Nanosheets: Green Photocatalytic Synthesis and Application toward the Degradation of Organic Pollutants. ACS Appl. Mater. Interfaces 2013, 5, 6815-6819. [CrossRef]

42. Fu, J.; Chang, B.; Tian, Y.; Xi, F.; Dong, X. Novel C3N4-CdS composite photocatalysts with organic-inorganic heterojunctions: In situ synthesis, exceptional activity, high stability and photocatalytic mechanism. J. Mater. Chem. A 2013, 1, 3083. [CrossRef]

43. Huang, L.; Xu, H.; Li, Y.; Li, H.; Cheng, X.; Xia, J.; Xu, Y.; Cai, G. Visible-light-induced WO3/gC3N4 composites with enhanced photocatalytic activity. Dalton Trans. 2013, 42, 8606-8616. [CrossRef]

44. Kuriakose, S.; Choudhary, V.; Satpati, B.; Mohapatra, S. Facile synthesis of Ag-ZnO hybrid nanospindles for highly efficient photocatalytic degradation of methyl orange. Phys. Chem. Chem. Phys. 2014, 16, 17560-17568. [CrossRef]

45. Kadam, A.; Kim, T.G.; Shin, D.-S.; Garadkar, K.M.; Park, J. Morphological evolution of Cu doped ZnO for enhancement of photocatalytic activity. J. Alloys Compd. 2017, 710, 102-113. [CrossRef]

46. Barzgari, Z.; Ghazizadeh, A.; Askari, S.Z. Preparation of Mn-doped ZnO nanostructured for photocatalytic degradation of Orange G under solar light. Res. Chem. Intermed. 2015, 42, 4303-4315. [CrossRef]

47. Kumar, R.; Umar, A.; Rana, D.S.; Sharma, P.; Chauhan, M.; Chauhan, G.S. Fe-doped ZnO nanoellipsoids for enhanced photocatalytic and highly sensitive and selective picric acid sensor. Mater. Res. Bull. 2018, 102, 282-288. [CrossRef]

48. Kumar, S.; Singh, V.; Tanwar, A. Structural, morphological, optical and photocatalytic properties of Ag-doped ZnO nanoparticles. J. Mater. Sci. Mater. Electron. 2015, 27, 2166-2173. [CrossRef]

49. Ji, Z.; Luo, Z.; Li, J.; Li, P. Enhanced Photocatalytic Activity of ZnO Toward the Degradation of Methylene Blue Dye: Effects of $\mathrm{Fe}^{3+}$ and $\mathrm{Sn}^{4+}$ Doping. Phys. Status Solidi 2019, 216, 1800947. [CrossRef]

50. Raghavan, N.; Thangavel, S.; Venugopal, G. Enhanced photocatalytic degradation of methylene blue by reduced graphene-oxide/titanium dioxide/zinc oxide ternary nanocomposites. Mater. Sci. Semicond. Process. 2015, 30, 321-329. [CrossRef] 
51. Tien, H.N.; Luan, V.H.; Hoa, L.T.; Khoa, N.T.; Hahn, S.H.; Chung, J.S.; Shin, E.W.; Hur, S.H. One-pot synthesis of a reduced graphene oxide-zinc oxide sphere composite and its use as a visible light photocatalyst. Chem. Eng. J. 2013, 229, 126-133. [CrossRef]

52. Liu, L.; Ma, D.; Zheng, H.; Li, X.; Cheng, M.; Bao, X. Synthesis and characterization of microporous carbon nitride. Microporous Mesoporous Mater. 2008, 110, 216-222. [CrossRef]

53. Li, X.; Zhang, J.; Shen, L.; Ma, Y.; Lei, W.; Cui, Q.; Zou, G. Preparation and characterization of graphitic carbon nitride through pyrolysis of melamine. Appl. Phys. A 2008, 94, 387-392. [CrossRef]

54. Le, S.; Jiang, T.; Li, Y.; Zhao, Q.; Li, Y.; Fang, W.; Gong, M. Highly efficient visible-light-driven mesoporous graphitic carbon nitride/ZnO nanocomposite photocatalysts. Appl. Catal. B Environ. 2017, 200, 601-610. [CrossRef]

55. Isai, K.A.; Shrivastava, V.S. Photocatalytic degradation of methylene blue using $\mathrm{ZnO}$ and $2 \% \mathrm{Fe}-\mathrm{ZnO}$ semiconductor nanomaterials synthesized by sol-gel method: A comparative study. SN Appl. Sci. 2019, 1, 1247. [CrossRef]

56. Mao, Y.; Wu, M.; Li, G.; Dai, P.; Yu, X.; Bai, Z.; Chen, P. Photocatalytic degradation of methylene blue over boron-doped g-C3N4 together with nitrogen-vacancies under visible light irradiation. React. Kinet. Mech. Catal. 2018, 125, 1179-1190. [CrossRef]

57. Adeleke, J.; Theivasanthi, T.; Thiruppathi, M.; Swaminathan, M.; Akomolafe, T.; Alabi, A. Photocatalytic degradation of methylene blue by ZnO/NiFe2O4 nanoparticles. Appl. Surf. Sci. 2018, 455, 195-200. [CrossRef]

58. Li, Y.; Wang, K.; Wu, J.; Gu, L.; Lu, Z.; Wang, X.; Cao, X. Synthesis of highly permeable Fe 2 O 3/ZnO hollow spheres for printable photocatalysis. RSC Adv. 2015, 5, 88277-88286. [CrossRef]

59. Zhu, H.Y.; Jiang, R.; Fu, Y.Q.; Li, R.R.; Yao, J.; Jiang, S.T. Novel multifunctional NiFe2O4/ZnO hybrids for dye removal by adsorption, photocatalysis and magnetic separation. Appl. Surf. Sci. 2016, 369, 1-10. [CrossRef]

60. Chen, L.; Jiang, D.; He, T.; Wu, Z.; Chen, M. In-situ ion exchange synthesis of hierarchical AgI/BiOI microsphere photocatalyst with enhanced photocatalytic properties. CrystEngComm 2013, 15, 7556. [CrossRef]

61. Malathi, A.; Arunachalam, P.; Madhavan, J.; Almayouf, A.M.; Ghanem, M.A. Rod-on-flake $\alpha$-FeOOH/BiOI nanocomposite: Facile synthesis, characterization and enhanced photocatalytic performance. Colloids Surf. A Physicochem. Eng. Asp. 2018, 537, 435-445. [CrossRef]

62. Fu, H.; Xu, T.; Zhu, S.; Zhu, Y. Photocorrosion Inhibition and Enhancement of Photocatalytic Activity for ZnO via Hybridization with C60. Environ. Sci. Technol. 2008, 42, 8064-8069. [CrossRef]

(C) 2020 by the authors. Licensee MDPI, Basel, Switzerland. This article is an open access article distributed under the terms and conditions of the Creative Commons Attribution (CC BY) license (http://creativecommons.org/licenses/by/4.0/). 